\title{
Traditional Arabic Costume and Indian Salwar Kameez: A Reciprocal Correlation
}

\author{
Dr. Monisha Kumar ${ }^{1}$ and Dr. Amita Walia ${ }^{1}$ \\ ${ }^{1}$ Assistant Professor, Fashion Design Department, Dar Al-Hekma University, Jeddah, KSA \\ ${ }^{2}$ Assistant Professor, Department of Fabric \& Apparel Science, University of Delhi, India
}

\begin{abstract}
In the recent years the Salwar Kameez has become an integral part of women's costume in the Indian subcontinent. Yet only few are aware of its true origin. The present day Salwar Kameez, also popular as one of the traditional Indian costumes today, traces back its origin to the Persian influence which was brought to India by the Mughals who followed Islam. This exchange of cultures with reference to the Salwar Kameez is an interesting aspect for study which focuses on the connection of these two different worlds. The research involves the study of traditional Arabic costumes and its correlation with Indian Salwar Kameez. In the pursuit of being modern, these countries have lost their traditional costumes whereas in India this has become an integral part of their traditional costume. The findings of the present study thus collected revealed a comprehensive picture of the past and the present scenario of the Salwar Kameez in the Arab world and the Indian subcontinent. Interesting facts related to origin, influence, acceptance and adaptation in the Indian culture and the reciprocal correlation between the Arab and Indian women's costumes were also discovered.
\end{abstract}

Keywords: Traditional, Arabic Costume, Salwar Kameez, Correlation.

\section{Introduction}

Clothing is one of the three primary needs of a human being like the other two- food and shelter. Clothes are not only used to cover the body but also serve as a significant nonverbal communication that establishes the cultural identity including a person's community or country of origin at any given historical period. The online Oxford dictionary defines the word "Culture is a word for people's way of life. A culture is passed on to the next generation by learning. Culture can be seen in people's writings, religion, music, costumes, cooking and what they do". Traditional costumes have been an integral part of any culture and are having been passed on from generation to generation. The culture of a country is also represented by the way people dress. The research involves the study of traditional Arabic costumes, their influence on the Indian costumes and vice versa with particular reference to Salwar Kameez. The costumes which once belonged to the Arabs now belong to the Indian subcontinent. These costumes have merely become occasional wear in these countries. The Indian theme wedding events are very popular among the young generation of the Arab world. This exchange of cultures with reference to the costumes is an interesting aspect for study which focused on the connection of these two different worlds. The locale of the research study is the Indian subcontinent and the Middle Eastern countriesOman and Saudi Arabia.

The following objectives were framed to study

- the Traditional Arabic Costumes

- the present status of Salwar Kameez in the Indian subcontinent.

- the reciprocal correlation of Indian Salwar Kameez and the Middle Eastern (Arabic) women's costume.

$\bullet$ 


\section{Traditional Arabic Costumes}

The cultural identity of any region can be depicted by fashion and the garments worn by the natives of that region. However there are many regional differences in the traditional costume of the Middle East (Arabian Peninsula), the main garments are the 'Dishdasha / Thobe/ Kaftan' an upper garment made from heavily embroidered fabric in bright colors mostly ankle length. Under this 'Dishdasha/ Thobe/ Kaftan' is a lower garment known as 'Sirwaal/Sarwal' which is a drawstring trouser generally tighter at the ankle. The 'Lihaf/Shal' is a head covering worn over the head. The 'Shal' is mostly black in color. Another important aspect of the women's garments is the veil or 'Burkha' - the face covering. In some parts of Arabia and Middle East, the women cover their faces in public. The veil also differs from region to region.

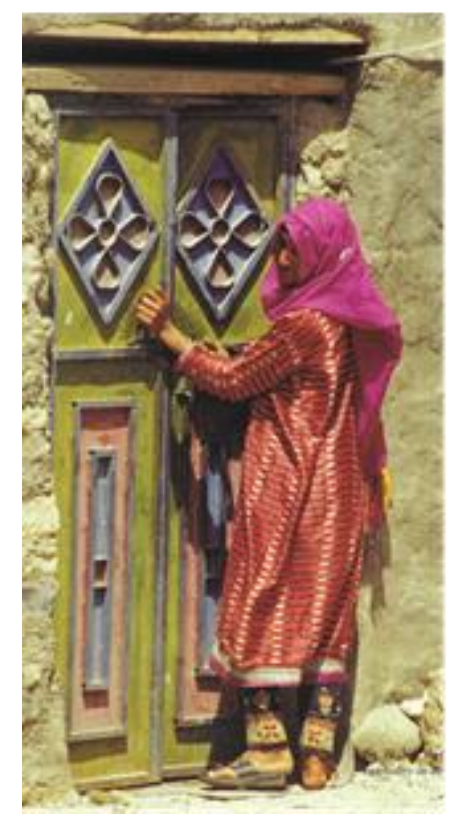

Fig. 1: Traditional Omani Women's Costume [1]

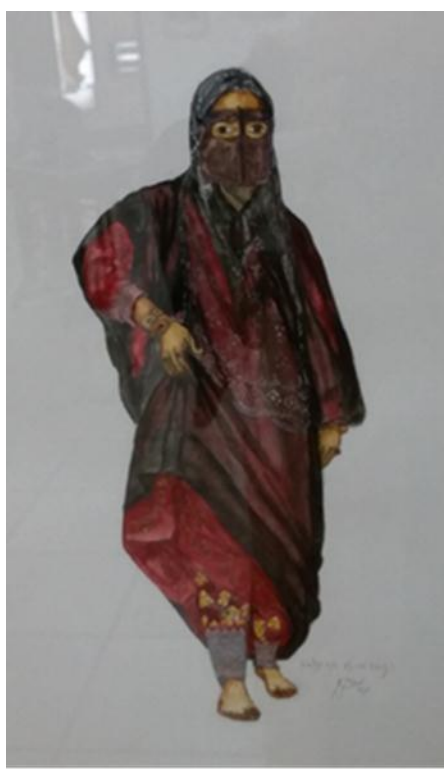

Fig. 2: Traditional Saudi Arabian Women’s Costume [4]

\subsection{Traditional Women's Costume in Sultanate of Oman}

The Sultanate of Oman possess a beautiful and extensive history and is considered the "hidden corner of Arabia". Oman shares its geographical borders with three other Arabic countries - Republic of Yemen, Kingdom of Saudi Arabia and United Arab Emirates. Many cultural similarities between these countries are noticeable in terms of food, lifestyle, traditions and costumes. However being closest to the Indian subcontinent, traces of rich Indian textiles are visible in the traditional costumes for women in the country. However the garments of the Arab world have been accepted and adapted by the Indian culture and have become synonymous with the Indian traditional costumes for men and in particular for women. Salwar Kameez is the best example to the track its route into the Indian culture.

There are various regional styles of women's costume in Oman. The styles of different regions are distinguished on the basis of material, cut, color and embellishments. However, all the regions have three basic elements for a women's costume -

- Dishdasha ( a dress)

- Sarwal (a pair of trousers)

- A form of head covering. 


\subsubsection{Dishdasha}

Dishdasha (Fig. 3) is a long tunic like garment worn by both men and women in Oman. The construction for both is more or less the same with the difference being in the length and the type of fabric used. The Dishdasha for women is generally mid-calf length, colorful and embellished. It is a straight cut silhouette with three panels each in the front and the back. The armholes are squared to fit the rectangular full length sleeves.

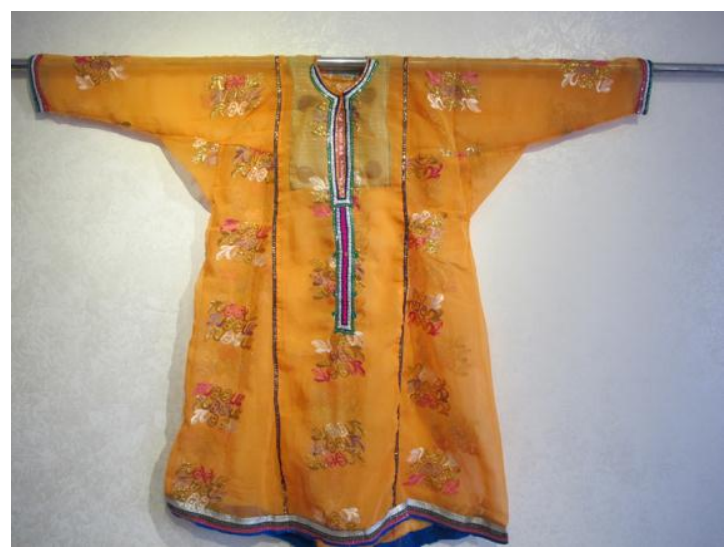

Fig. 3: Dishdasha [1]

\subsubsection{Salwar}

Salwar is a lower garment worn under the Dishdasha which is narrow at the ankle and tied with a drawstring at the waist. The Salwar is constructed on a straight grain. There are two different types of Salwar worn in Oman. The construction for both the types is almost the same with the only difference being in the size of opening for the foot to go in. Fig. 4 shows the type of Salwar which is loose straight cut trouser with an ankle cuff. Fig.5 shows the type of Salwar with is quite narrow from hip down till the ankle. Sometimes the opening at the ankle is so narrow that the women have to wear a plastic bag on their foot to pull it up.

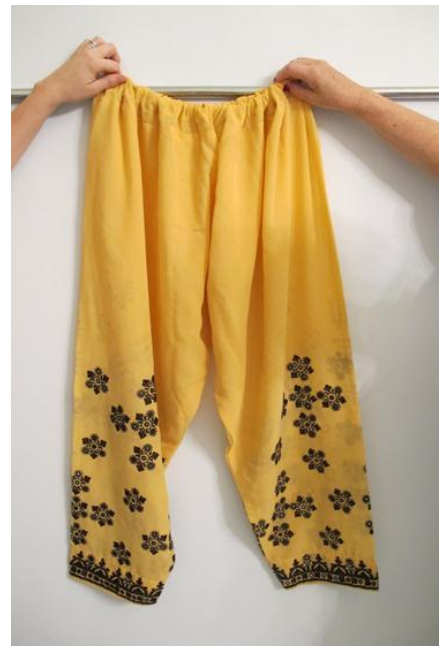

Fig. 4: Salwar with ankle cuff [1]

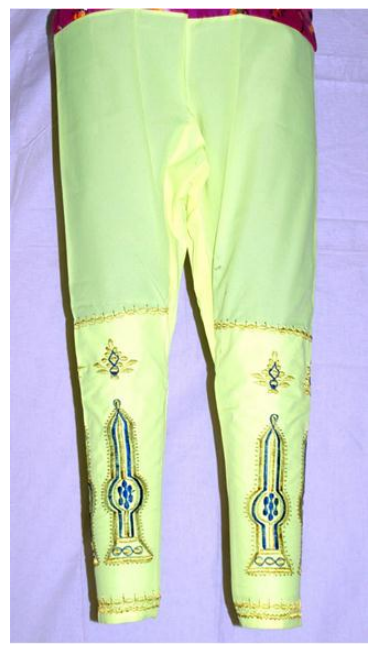

Fig. 5: Salwar with narrow ankle [1]

\subsection{Traditional Women's Costume in Saudi Arabia}

Kingdom of Saudi Arabia is the second-largest state in the Arab world after Algeria. Saudi Arabia is bordered by Jordan and Iraq to the north, Kuwait to the northeast, Qatar, Bahrain and the United Arab Emirates to the east, Oman to the southeast and Yemen to the south. Saudi Arabian dress strictly follows the principles of Hijab (the Islamic principle of modesty). Women's clothes are often decorated with tribal motifs, coins, sequins, 
metallic thread, and appliques. In public women are required to wear a black Abaya that covers everything under the neck. The traditional Arabian women's costumes are voluminous, flowing and are richly embroidered with geometric patterns in bold colors. As seen in Sultanate of Oman, there are regional variations in the costume which are clearly visible. The basic garments which form the complete women's costume in the Arabian region are-

- Kaftan/Thawb- long length tunic

- Sirwaal- a pair of trousers

- Head covering/Shaal

- Burka/Nikaab- veil to cover the face

- Abaya- mantle or cloak usually black in color worn in public.

\subsubsection{Kaftan}

The Kaftan (Fig. 6) is a loose body shirt and is the basis of Arabian costume. The original design incorporated the use gusset for the sleeves and panels in the garment. It is known by various names in classical and colloquial Arabic such as Qamis, Thawb, Jubba, Kirta, Ghilala and Dishdasha to name a few.

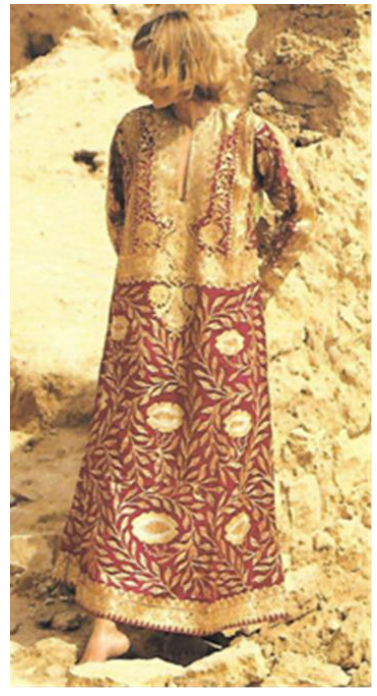

Fig.6: Kaftan [2]

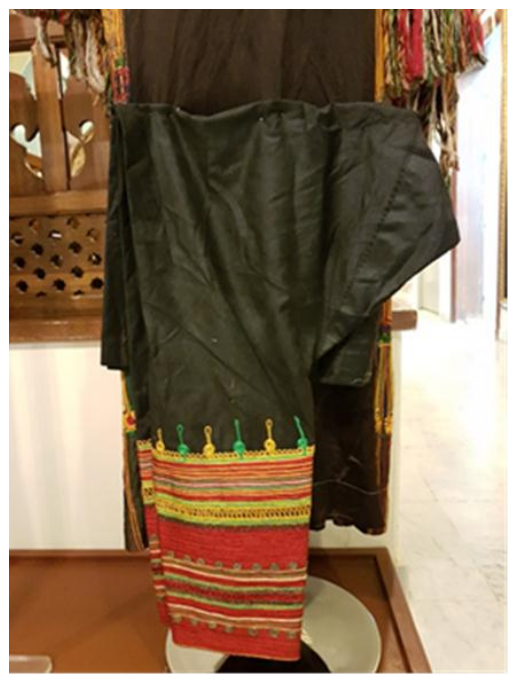

Fig. 7: Arabian Sirwaal [4]

\subsubsection{Sirwaal/Shirwal}

The basic construction of the Sirwaal is a straight cut with narrow opening at ankle tied at the waist with a drawstring. The Arabian Sirwaal (Fig.7) does not have any panel and waist belt instead it has a rectangular crotch gusset for freedom of movement at the hip area. The lower portion is narrow till the ankles. The Sirwaal is gathered at the waistband which is threaded with a drawstring known as Dikka in local language.

\subsection{Indian Salwar Kameez}

Due to the Persian and Turkish domination in Central Asia; the presence of Salwar Kameez was seen as an expression of Indian traditional costume. Research and historical records have proved that the pattern prevalent today in India are indeed the descendant of Turkish and Persian forms of Salwar Kameez. The Salwar Kameez has become popular among the young generation because it is comfortable, elegant and most respected apparel. The Salwar Kameez worn in India has the following three components

- Kameez/Kurta - a tunic or dress

- Salwar/Shalwar- a pair of trousers

- Dupatta- a rectangular scarf used as a head covering. 


\subsubsection{Kameez and its Variations}

The traditional Kameez top is a loose-fitting, knee-length tunic with long sleeves. The tunic is worn by pulling it over the head through a round neckline that has a front slit. The Kameez has seen a lot of style variations over the decades and has been called by various names (Fig.8).
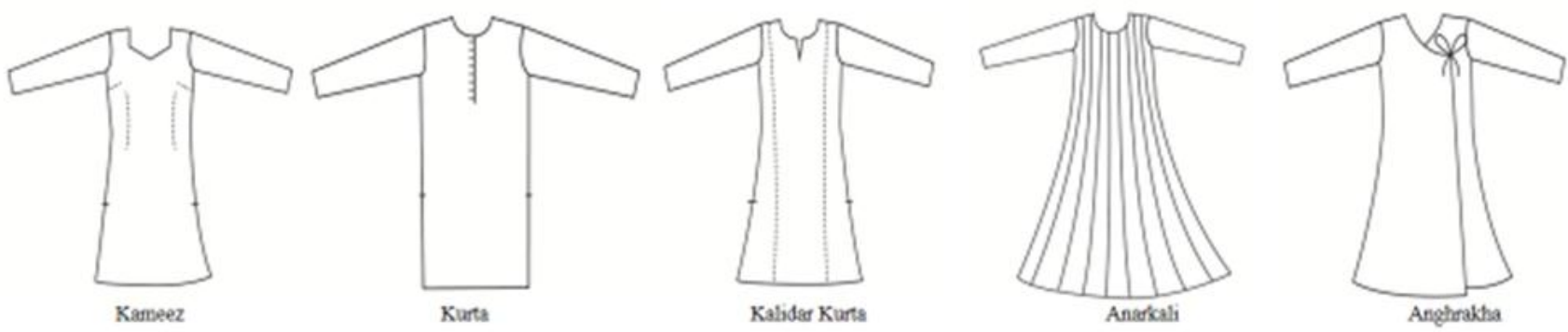

Fig. 8: Style Variations of Indian Kameez [4]

\subsubsection{Salwar and its variations}

Indian Salwar resemble a Pajama drawn tightly at the waist with a string and is tailored in such a way that it tapers at the ankles. The Indian Salwar has seen a lot more style variations than the Kameez. There are different names for different styles (Fig.9).

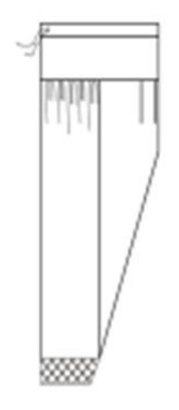

Salwar

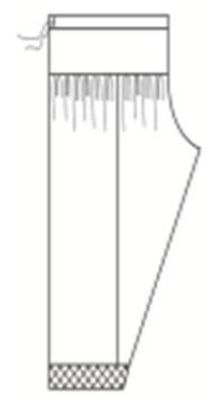

Patiala Saluzr

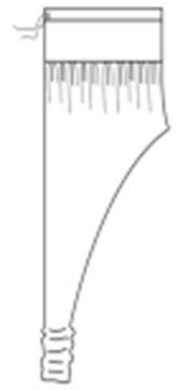

Churidar

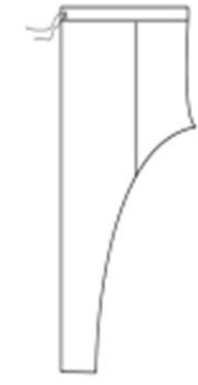

Aligarhi Pajema

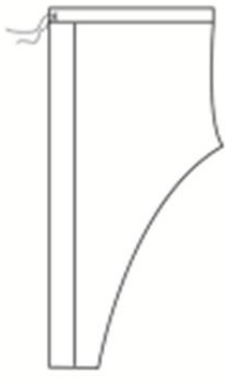

Slim Pants

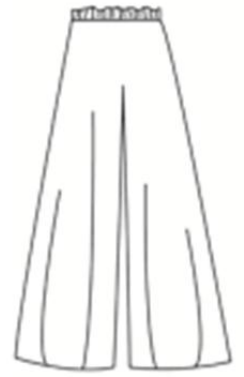

Palszzo

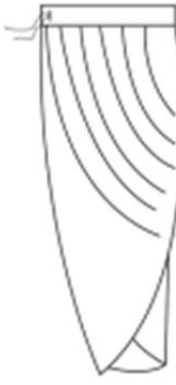

Dboti Salvar

Fig.9: Style Variations of Salwar [4]

The Salwar Kameez is usually paired with a long, sheer fabric scarf or shawl known as a Dupatta, which is either draped across the neck or over the head which is both a mark of respect and honor.

\section{Reciprocal Correlation}

"Clothing is a cultural phenomenon and an aesthetic medium for the expression of ideas and beliefs circulating in society" [3]. Centuries of invasions, conquest and trade links between the subcontinent and the Arab world has contributed to the blending of cultures and traditions not only in clothing but also in food habits and lifestyle.The similarities between the Indian Salwar Kameez and the Arabic Costumes clearly show the amalgamation of cultures. 
The Dishdasha from Oman and Kaftan from Saudi Arabia are similar in appearance and construction to the Kalidar Kurta seen in the Indian subcontinent (Fig.10). A Kalidar Kurta has six panels (three in the front and three at the back). The side panels for both front and back are cut at an angle on one side and straight on the other. It has long and loose sleeves. There is a triangular piece attached between the sleeve and the bodice of the garment called gusset to give extra looseness to the garment.

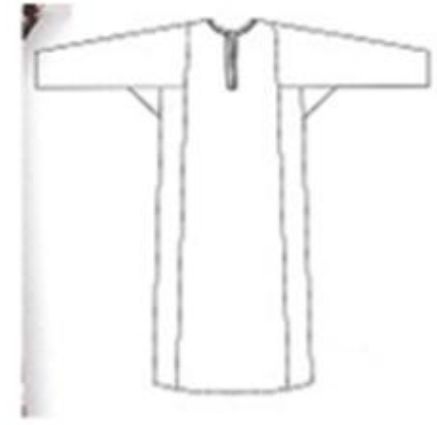

Omani Dishdasha

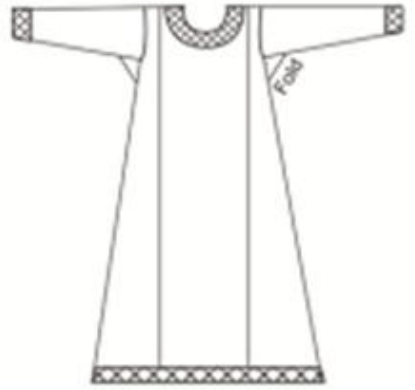

Arabian Thobe/Kaftan

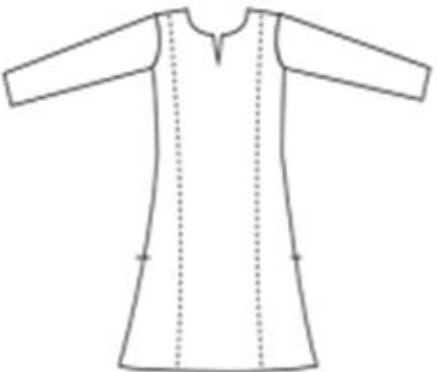

Indian Kalidar Kurta

Fig.10: Correlation between Omani Dishdasha, Arabian Kaftan and Indian Kalidar Kurta w.r.t construction [4]

There are similarities between the Omnai Sarwal, the Arabian Sirwaal and Aligarhi Pajama style Salwar from Indian subcontinent (Fig.11). The Omani Sarwal is exactly the same as the Aligarhi Pajama in appearance and construction. Some styles have a wider opening for the foot resembling the Salwar from Indian subcontinent. The Arabian Sirwaal, unlike the Aligarhi Pajama, does not have any panel and waist belt instead it has a rectangular crotch gusset for freedom of movement at the hip area. The lower portion is narrow till the ankles.

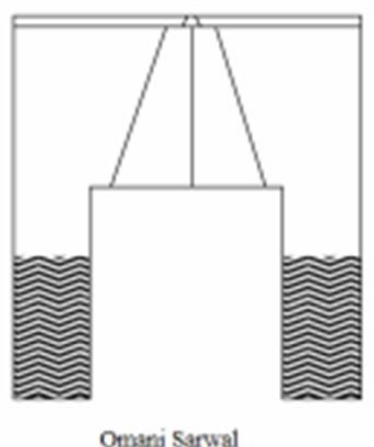

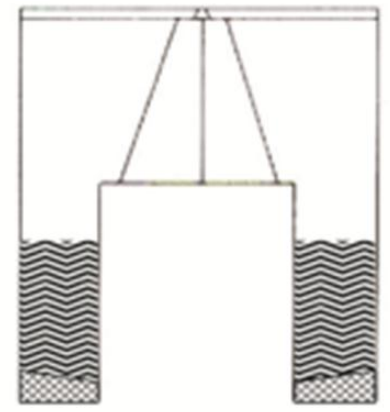

Arabian Sirazal

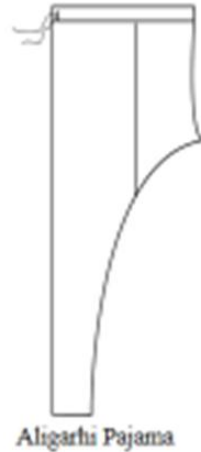

Aligarhi Pajama

Fig.11: Correlation between Omani Sarwal, Arabian Sirwaal and Indian Aligarhi Pajama w.r.t construction [4]

The constructional details of Salwar/Sirwal and Kameez /Dishdasha/Kaftan/Thobe have clearly revealed the similarity in construction. There has been a considerable change in the cultural identity of both the Indian Subcontinent and the Middle Eastern countries popularly known as the Arab countries with respect to women's costume. After extensive study and analysis, it can be easily inferred that the traditional dress of Persian (Iranian) and Turks travelled to the subcontinent during the medieval period. This easily got amalgamated into the culture of Indian subcontinent and with transformation over time, a unique style was created. 


\section{References}

[1] J. M Alzadjali, The Traditional Women's Dress of Oman, 1st ed. Muscat: Muscat Press \& Publishing House, 2010.

[2] H. C. Ross, The Art of Arabian Costumes- A Saudi Arabian Profile. U.K: Players Press. 1995

[3] E. Wilson, Adorned in dreams: fashion and modernity, Tauris, London, 2003

[4] M. Sobti, "Reciprocal Influence of Indian and Persian Women's Costume," PhD dissertation, Faculty of Fashion Technology, PAHER Univ., Udaipur, India, 2017. 